\title{
Colloidal Polymeric Platform for Facile Click-Assisted Ligand Functionalization and Receptor Targeting
}

\author{
Ruhani Singh, ${ }^{\dagger}$ Diwei Ho, ${ }^{\dagger}$ Lee Yong Lim, ${ }^{\dagger}$ K. Swaminathan Iyer, ${ }^{* \dagger}$ and Nicole M. Smith ${ }^{*},{ }^{\dagger} \S$ \\ ${ }^{\dagger}$ School of Chemistry and Biochemistry, M310, ${ }^{\ddagger}$ School of Medicine and Pharmacology, M315, and ${ }^{\S}$ School of Animal Biology, \\ M092, The University of Western Australia, 35 Stirling Highway, Crawley, Western Australia 6009, Australia
}

\section{Supporting Information}

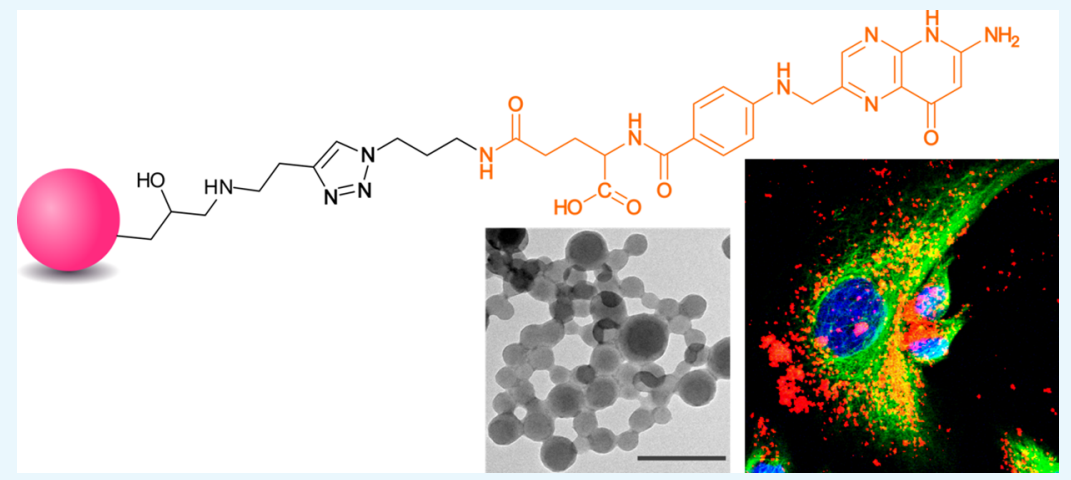

ABSTRACT: Colloidal poly(glycidyl methacrylate) nanoparticles (NPs) are demonstrated to be platforms facilitating the "click" chemistry approach of surface functionalization for receptor targeting. Folate receptor-targeted NPs were synthesized, physicochemically characterized, confirmed for their biocompatibility, and validated for their selective targeting capabilities for ovarian cancer cells in vitro.

\section{INTRODUCTION}

Most chemotherapeutic and macromolecular anticancer drugs are designed to interfere with cell proliferation and are inherently nondiscriminating in nature. They nonspecifically affect both the highly proliferative cancer cells and the normal fast-dividing cells, leading to acute and sometimes potentially chronic side effects. ${ }^{1}$ For this reason, a class of anticancer agents that utilize targeting moieties for their selective delivery to malignant cells is highly desirable. ${ }^{2}$ A common strategy involves targeting moieties that specifically bind to receptors overexpressed on cancer cells being conjugated either directly to the drug or to a nanoparticle (NP) drug carrier for targeted therapy. NP-based delivery offers both the possibility of multifunctionality and higher targeting potential via a multivalent binding process owing to tuneable ligand density on their surface. ${ }^{3}$ In the case of polymeric NPs, targeting ligands can be conjugated to the polymer before emulsification or to the surface of an emulsified colloidal polymeric NP. The latter approach is preferable because the former alters the polymer lipophilicity and, consequently, the drug encapsulation efficiency. ${ }^{4}$ The former method is also susceptible to ligand entrapment within the NP core post emulsification, resulting in insufficient availability for receptor interaction on the cell surface. ${ }^{4}$ Indeed, the more efficient approach of attachment onto the NP surface will permit targeting moieties to be deposited only on the surface. ${ }^{5}$ However, ligand attachment on colloidal NPs using conventional chemical conjugation approaches is limited by the possibility of NP instability and aggregation. Most of the conventional coupling strategies are nonspecific in nature. This can lead to undesired interactions of the targeting ligand with the NP payload (drug, imaging agent, etc.) causing loss in functionality of either or both. ${ }^{6}$ Additionally, modification strategies on colloidal NPs suffer from poor control of reaction yields, difficulty in purification of NPs from byproducts, and difficulty characterizing the resulting NP conjugates. ${ }^{5}$ Furthermore, biomolecules such as vitamins, proteins, peptides, and antibodies are the most commonly used targeting moieties. These molecules are sensitive to denaturation and degradation in nonphysiological reaction conditions such as the presence of organic solvents or exposure to heat and light, compromising their biological function and affinity for the receptor. Additionally, they are required to be conjugated in a particular orientation for their receptor recognition. For these aforementioned reasons, newer and better bioconjugation approaches such as "click" chemistry have been recently adopted. ${ }^{7}$ Click reactions are high-yielding, stereospecific, wide in scope, and generate either no byproducts or byproducts that can be easily removed by nonchromatographic methods. ${ }^{8}$ The processes use simple reaction conditions and a solvent-less approach or benign solvents such as water. ${ }^{8}$ However, using click chemistry for bioconjugation reactions requires prefunc-

Received: September 26, 2016

Accepted: October 17, 2016

Published: December 6, 2016 
Scheme 1. Schematic Representation of the Reactions ${ }^{a}$

(i)

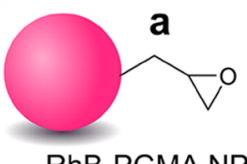

RhB-PGMA NP

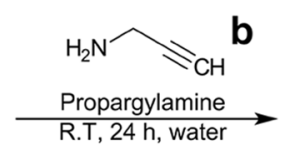

R.T, 24 h, water

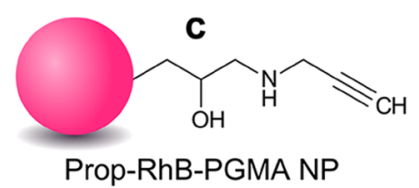

Prop-RhB-PGMA NP

(ii)<smiles></smiles>

Prop-RhB-PGMA NP

Azido-Folic acid

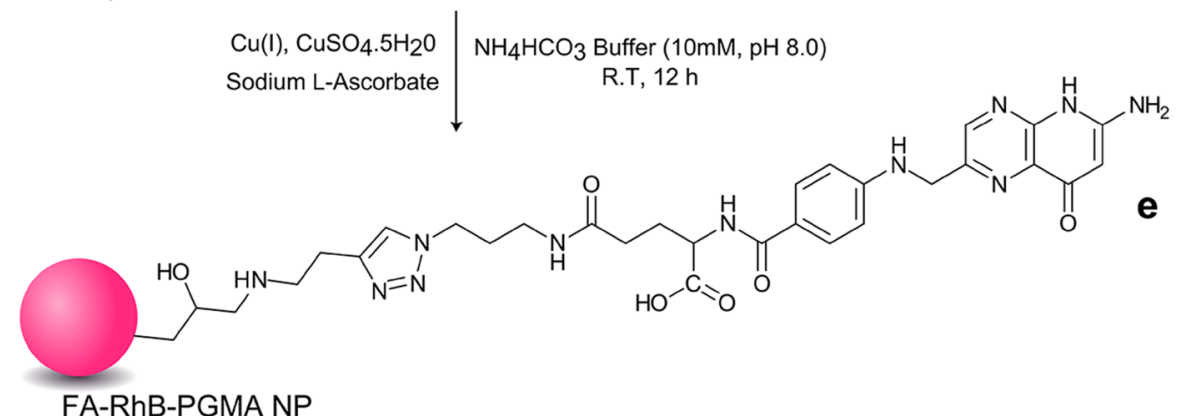

${ }^{a}$ (i) Propargylation of rhodamine B-labelled PGMA NPs (RhB-PGMA NPs) using epoxide ring-opening reaction and (ii) the CuAAC click reaction, leading to the synthesis of fluorescent folic acid-functionalized PGMA NPs (FA-RhB-PGMA NPs).

tionalization of the starting materials to make them amenable to click reactions, resulting in a tedious multistep process.

Herein, we demonstrate the use of poly(glycidyl methacrylate) (PGMA)-based NPs as versatile platforms for facile clickassisted conjugation of targeting ligands. In this work, the targeting ligand-folic acid (FA) - was conjugated on colloidal PGMA NPs via two simple steps: first, an epoxide ring-opening reaction followed by a copper-catalyzed alkyne-azide cycloaddition $(\mathrm{CuAAC})$ click reaction, both using only mild aqueous conditions (Scheme 1). We further demonstrate that conjugating FA to NPs using this strategy can efficiently direct the NPs to bind selectively to folate receptor- $\alpha$ (FR $\alpha)$ overexpressing ovarian cancer cells in vitro.

FA was chosen as a model system in the present study because it is an essential vitamin that plays a central role in DNA synthesis, repair, and methylation; therefore, the proliferation and maintenance of all cells. ${ }^{9}$ FRs are upregulated in cancer cells, resulting in elevated receptor-mediated uptake of FA. This in turn enables highly proliferating malignant cells to compete more aggressively for the vitamin. ${ }^{10}$ Importantly, the FR $\alpha$ isoform is well known to have elevated levels of expression in various human malignancies of the epithelial lineage, particularly in $82 \%$ of ovarian cancers. ${ }^{11}$ The high nanomolar affinity of FA for FR $\alpha^{12}\left(K_{\mathrm{d}}<10^{-9} \mathrm{M}\right)$ along with relatively high storage, stability, availability, cost effectiveness, and ease of chemical attachment and characterization makes FA a pertinent ligand for conjugation. For this reason, a large number of FA-functionalized polymeric NPs for application in tumor-targeted therapy and imaging have previously been reported. ${ }^{13}$

Recent determination of the crystal structure of the human FR $\alpha$ in complex with FA confirms that the carboxylate groups in FA are the optimal regions for its conjugation to NPs without affecting its receptor affinity. ${ }^{14}$ In addition, the greatest degree of FR binding has been noted for an optimal FA surface density on NPs compared with higher or lower density variants. $^{15}$ A carbodiimide reaction [ $N$-hydroxysuccinamide/ $N, N^{\prime}$-dicyclohexylcarbodiimide (NHS/DCC)] that facilitates condensation of amino and carboxylic groups giving rise to a stable amide linkage is the most commonly used methodology for FA conjugation to the aforementioned polymeric NPs. ${ }^{4}$ This approach has its drawbacks, which include difficulty in purification from byproducts and multistep isolation, leading to NP agglomeration. Overall, this process results in poor control of the ligand density and low ligand-binding efficiency on the NPs. ${ }^{4,16}$ Herein, we propose the utility of colloidal PGMA for facile click-assisted ligand conjugation.

\section{RESULTS AND DISCUSSION}

The reactive epoxide functionalities make PGMA a very versatile polymer that is ideal for both synthesis of NPs and their facile modification. The PGMA NPs were synthesized using an oil-in-water emulsification process (Supporting Information). The polymer was modified with a fluorescent dye, rhodamine $\mathrm{B}(\mathrm{RhB})$, using a previously reported procedure to render the colloidal system suitable for fluorescence imaging in vitro. ${ }^{17}$ The attachment occurred via an epoxide ring-opening reaction between the freely available carboxyl group on $\mathrm{RhB}$ and the epoxide group on PGMA, which was confirmed using ultraviolet-visible (UV-vis) spectrometry (Supporting Information). ${ }^{17}$ To make the NPs amenable to the CuAAC click reaction, it is necessary to functionalize the polymer either with an azide or alkyne functionality. Herein, the presence of epoxide groups in PGMA facilitated the introduction of terminal alkyne functionalities on NPs via a single-step nucleophilic substitution ring-opening reaction with propargylamine [Scheme $1(\mathrm{i})]$. Alternatively, the surface of an assembled NP can be azide-functionalized for the $\mathrm{CuAAC}$ reaction with alkyne-functionalized FA. ${ }^{18}$ However, to 
minimize the possibility of alkyne homocoupling side reactions, ${ }^{19}$ a sterically bulkier base, that is, the NP surface, was preferred for the introduction of the alkyne functionality in this work. Excess propargylamine was washed with water, yielding propargylated fluorescent PGMA NPs (Prop-RhBPGMA NPs). The Fourier transform infrared (FTIR) spectrum for rhodamine-labelled PGMA NPs (Figure 1a) shows

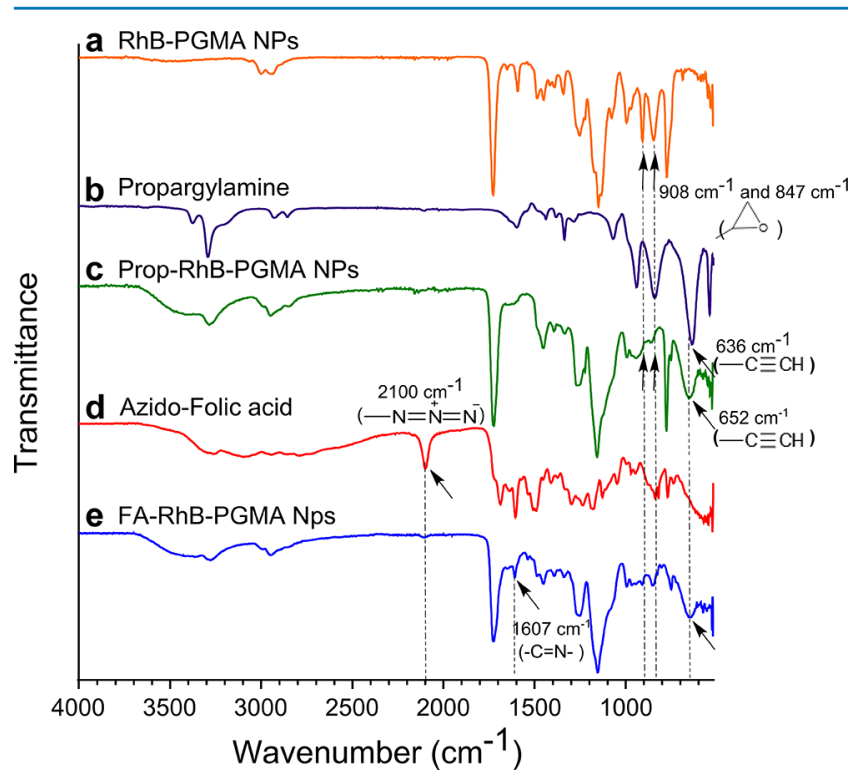

Figure 1. FTIR spectra of (a) RhB-PGMA NPs, (b) propargylamine, (c) Prop-RhB-PGMA NPs, (d) azido-folic acid, and (e) FA-RhBPGMA NPs. characteristic absorption bands for symmetric and asymmetric epoxide ring $(-j)$ deformations at 908 and $847 \mathrm{~cm}^{-1}$, respectively. Propargylamine has the characteristic $\mathrm{C}-\mathrm{H}$ bend $(-\mathrm{C} \equiv \mathrm{C}-\mathrm{H})$ peak at $636 \mathrm{~cm}^{-1}$ (Figure $\left.1 \mathrm{~b}\right)$. A corresponding band at $652 \mathrm{~cm}^{-1}$ appeared as shown in Figure 1c, confirming the introduction of a terminal alkyne on the polymer. Conversely, the bands at 908 and $847 \mathrm{~cm}^{-1}$ were distinctly reduced in intensity upon propargylamine attachment (Figure 1c).

An azide functionality was introduced in FA according to a previously reported method. ${ }^{20}$ Briefly, this involved a carbodiimide cross-linking reaction with the formation of an NHS ester of FA, followed by the addition of 3-azido-1propylamine. The primary amine on 3-azido-1-propylamine coupled with the activated glutamate moiety on FA produced the desired azido-folic acid product in $72 \%$ yield. The final product was confirmed using FTIR (Figure 1d) and proton nuclear magnetic resonance ( ${ }^{1} \mathrm{H}$ NMR) (Supporting Information) spectra.

The azide-functionalized FA was attached to the colloidal surface using the CuAAC click reaction. The reaction was performed under an atmosphere of argon under weakly basic conditions $\left(\mathrm{NH}_{4} \mathrm{HCO}_{3}\right.$ buffer, $\left.10 \mathrm{mM}, \mathrm{pH} 8.0\right)$ at room temperature for $12 \mathrm{~h}$ [Scheme 1(ii)]. These conditions are advantageous in maintaining the biological activity of FA because it is sensitive to heat, light, and acidic $\mathrm{pH}$. The copper(I)-catalyst was generated in situ by reducing copper(II)-sulphate using a freshly prepared sodium L-ascorbate solution. Post reaction, NPs were extensively washed to remove unreacted azido-folic acid and further dialyzed to remove the trace amounts of copper. Successful conjugation of the FA

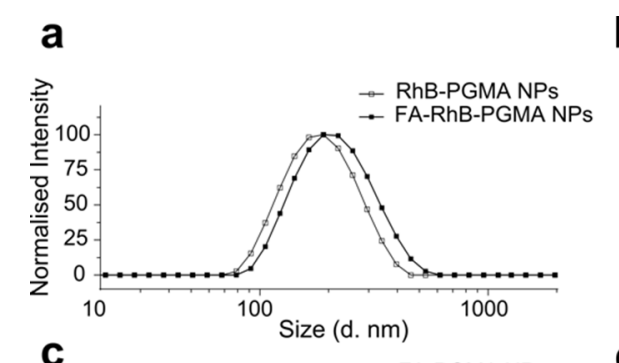

b
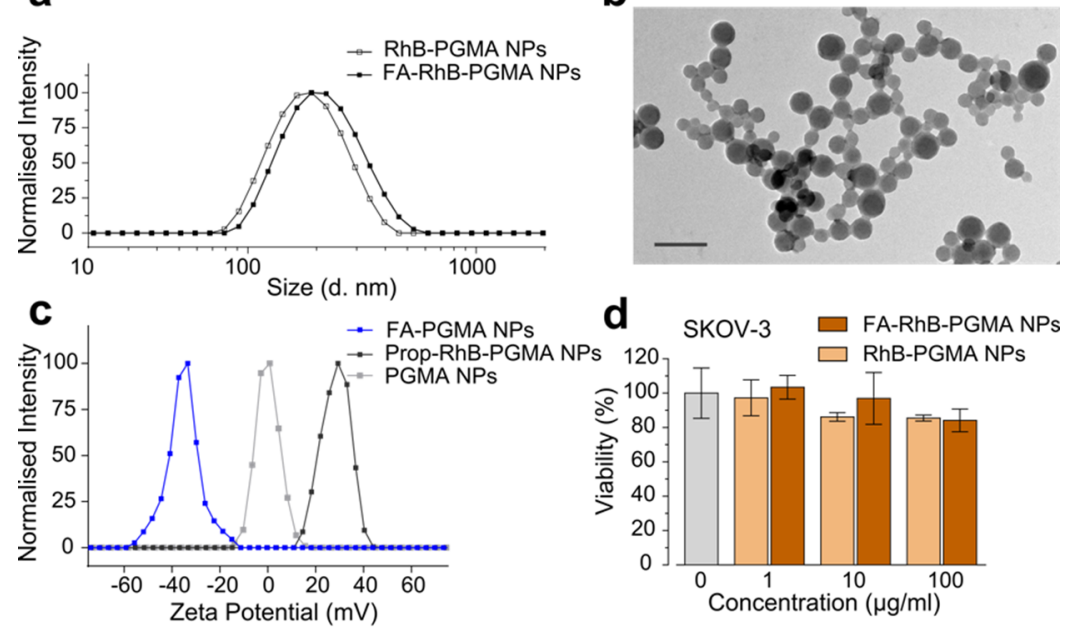

d SKOV-3 $\square$ FA-RhB-PGMA NPS
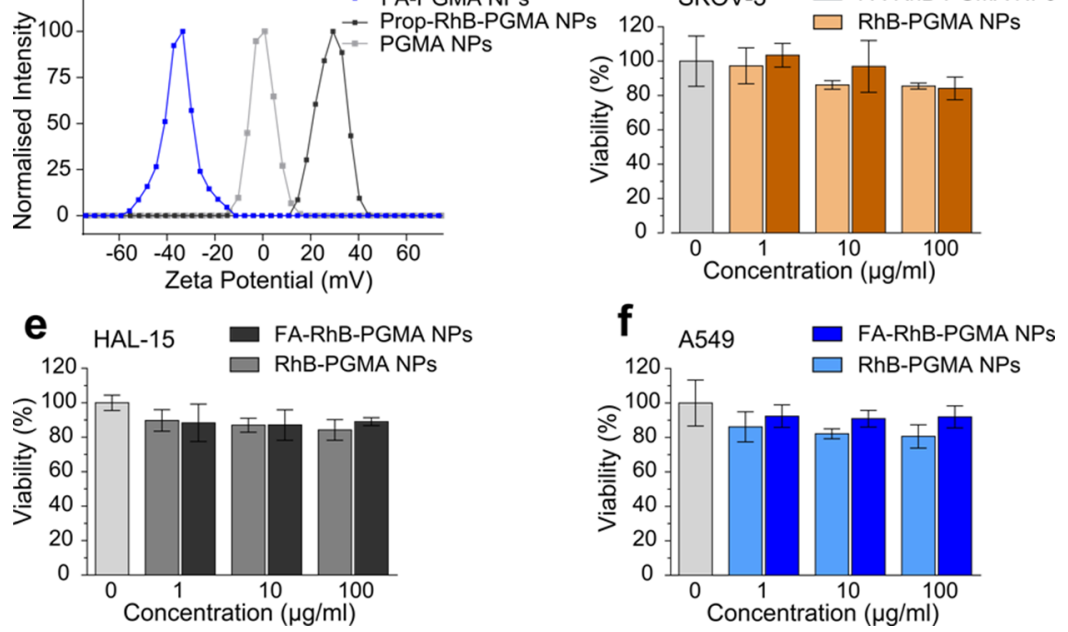

Figure 2. Physicochemical characterization and in vitro toxicity assessment of FA-RhB-PGMA NPs. (a) Particle size before (open) and after (solid) FA attachment. (b) TEM image of FA-RhB-PGMA NPs (scale bar, $250 \mathrm{~nm}$ ). (c) Change in zeta potential with surface functionalization of NPs. (df) In vitro cell viability and assessment of biocompatibility of RhB-PGMA NPs and FA-RhB-PGMA NPs at concentrations of 1, 10, and 100 $\mu \mathrm{g} / \mathrm{mL}$ in (d) SKOV-3, (e) HAL-15, and (f) A549 cells following a $72 \mathrm{~h}$ incubation period. 
a
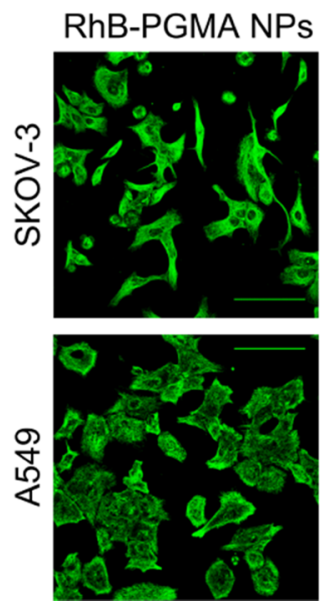
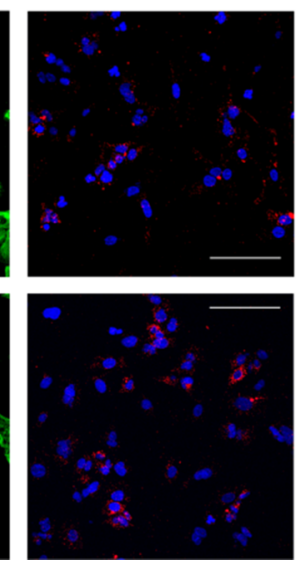

b

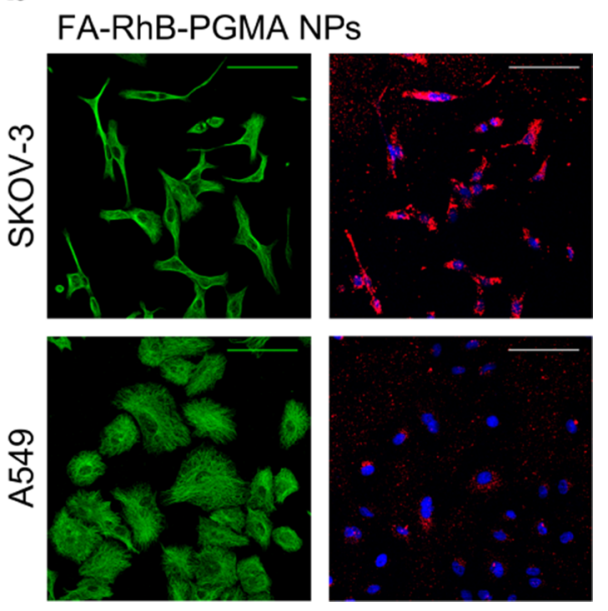

Figure 3. NP uptake in FR $\alpha$-overexpressing and FR $\alpha$-deficient cell lines. (a) RhB-PGMA NPs and (b) FA-RhB-PGMA NPs uptake in SKOV-3 (top) and A549 (bottom) cells (scale bar, $100 \mu \mathrm{m}$; on the left, images of cells stained green for $\alpha$-tubulin, and on the right, images of cells with cell nuclei stained blue and NPs fluoresce red due to the presence of RhB).

moiety onto NPs was confirmed using FTIR spectroscopy, wherein a new peak appeared at $1607 \mathrm{~cm}^{-1}$ (Figure 1e) corresponding to the $-\mathrm{C}=\mathrm{N}-$ stretch of the $1,2,3$ triazole ring, formed as a result of the CuAAC cycloaddition. Furthermore, the peak corresponding to the azide functionality $\left(-\mathrm{N}=\mathrm{N}^{+}=\mathrm{N}^{-}\right)$at $2100 \mathrm{~cm}^{-1}$ appearing in Figure 1d was absent in Figure 1e, indicating the absence of any reactant residue. However, a residual peak for free terminal alkyne groups $\left(652 \mathrm{~cm}^{-1}\right)$ in Figure 1e indicates incomplete reaction that could either be due to the early termination of reaction or the steric hindrance between FA functionalities on the NP surface. FA attachment to the NPs was also confirmed using UV-vis absorption spectra of FA-RhB-PGMA NPs containing characteristic peaks for both FA and RhB at 358 and $564 \mathrm{~nm}$, respectively (Supporting Information).

Synthesis and purification of RhB-PGMA and FA-RhBPGMA NPs were followed by their physicochemical characterizations. As shown in Figure 2a, analysis of the average hydrodynamic diameter of NPs revealed a shift from $193 \mathrm{~nm}$ [polydispersity index (PDI): 0.074] to $223 \mathrm{~nm}$ (PDI: 0.121) following FA attachment. This $\sim 20 \mathrm{~nm}$ increase in the average hydrodynamic diameter could presumably result both from the presence of an additional FA layer on the NPs and importantly from the resultant more solvated NP surface. The transmission electron microscopy (TEM) image (Figure 2b) suggests a spherical morphology for FA-RhB-PGMA NPs. The zeta potential for the NPs changed at each of the two steps leading to FA conjugation. Interestingly, there was an increase in the surface potential from near-neutral to $+29.4 \mathrm{mV}$ on attachment of neutral alkyne functionalities (propargylation) on the NPs. This reversed to a final negative surface charge $(-33.4 \mathrm{mV})$ on FA-RhB-PGMA NPs (Figure 2c), confirming the presence of an anionic layer of FA on NPs at physiological $\mathrm{pH}$ and suggesting colloidal stability. ${ }^{21}$ The amount of FA attached to the NPs calculated using UV-vis spectrometry was found to be $14.8 \%(\mathrm{w} / \mathrm{w})$ (Supporting Information). FA density on NPs can potentially be optimized in future by varying the reaction parameters and studying the effect of ligand density on their uptake in target cells.

Following the synthesis and physicochemical characterizations, the toxicity of the NPs was assessed in both human cancer and normal human cell lines. Briefly, three different cell lines-(1) HAL-15, primary cells from human liver, (2) SKOV3 , ovarian cancer cells, and (3) A549, lung adenocarcinoma cells-were incubated for $72 \mathrm{~h}$ with RhB-PGMA and FA-RhBPGMA NPs in cell-culture media at the NP concentrations of 1 , 10 , and $100 \mu \mathrm{g} / \mathrm{mL}$. Cell viability was tested using an MTS assay. As shown in Figure 2d, neither RhB-PGMA nor FA-RhBPGMA NPs displayed any significant toxicity [analysis of variance (ANOVA) with Tukey's post hoc, $p>0.05, n=3$ ] in SKOV-3 (Figure 2d), HAL-15 (Figure 2e), and A549 cell lines (Figure 2f).

Before assessing the active targeting capability of FA-RhBPGMA NPs for ovarian cancer cells, the relative overexpression of FR $\alpha$ on the chosen SKOV-3 cell line was confirmed. A flow cytometric analysis of $\mathrm{FR} \alpha$ expression (Supporting Information) showed that the receptor was overexpressed in the SKOV-3 cell line relative to A549 and HAL-15 cells. The targeting ability of FA-RhB-PGMA NPs was confirmed in vitro using fluorescence confocal laser scanning microscopy. Briefly, FR $\alpha$-overexpressing SKOV-3 cells and FR $\alpha$-deficient A549 cells were incubated with fresh cell culture media containing either $10 \mu \mathrm{g} / \mathrm{mL}$ RhB-PGMA NPs or $10 \mu \mathrm{g} / \mathrm{mL}$ FA-RhB-PGMA NPs. After a $12 \mathrm{~h}$ incubation period, the cell samples were fixed and stained for $\alpha$-tubulin and cell nuclei followed by microscopic analysis. Figure 3 shows the extent of cellular uptake of FA-conjugated and unconjugated NPs (NPs stained red for RhB) in FR $\alpha$-overexpressing SKOV-3 cells and FR $\alpha$ deficient A549 cells.

The cellular uptake profiles of RhB-PGMA NPs suggest that both SKOV-3 and A549 cells are capable of internalizing a small amount of NPs via non-FR $\alpha$-directed mechanisms (Figure 3a). However, there is a clear positive correlation between the presence of FA on NPs and their higher uptake in FR $\alpha$-overexpressing SKOV-3 cells (Figure 3b). On the other hand, NP uptake in A549 cells remains unaffected by FA conjugation, which suggests that the enhanced uptake of FARhB-PGMA NPs in SKOV-3 can be attributed to the FR $\alpha$ mediated uptake mechanism.

\section{CONCLUSIONS}

We report PGMA NPs as a colloidal polymeric platform for facile click chemistry-assisted ligand functionalization and 
receptor targeting. FA attachment on PGMA NPs was performed using a clean two-step process wherein only an aqueous solvent and ambient conditions were required and no side products were generated. The presence of a large amount of epoxide functionality on PGMA NPs facilitated a single-step prefunctionalization of NPs, making them amenable to clickfacilitated attachment of FA in the second step. The resultant biocompatible FR $\alpha$-targeted NPs demonstrated active targeting capability by enhanced accumulation in ovarian cancer cells in vitro, thereby confirming an orientation-controlled attachment of the targeting ligand using this approach.

\section{EXPERIMENTAL PROCEDURES}

NP Synthesis and Characterization. Materials. PGMA $\left(M_{\mathrm{n}}=220515 \mathrm{~g} / \mathrm{mol}, M_{\mathrm{w}}=433730 \mathrm{~g} / \mathrm{mol}, \mathrm{PDI}=1.97\right)$ was a generous gift from Prof. Igor Luzinov and Dr. Yuriy Galabura (School of Materials Science and Engineering, Clemson University, Clemson, SC, USA). RhB (>95\%, Kodak), ethyl methyl ketone (MEK) (>99\%, Sigma Aldrich), chloroform (>99\%, Chem-Supply), propargylamine (>99.8\%, Sigma Aldrich), Pluronic F108 (Sigma Aldrich), 3-azido-1-propylamine (>99.7\%, Alfa Aesar), dimethyl sulfoxide (DMSO, >99\%, Sigma Aldrich), FA (>97\%, Sigma Aldrich), DMSO-d 6 (99.9\%, Sigma Aldrich), $\mathrm{NH}_{4} \mathrm{HCO}_{3}$ (>99\%, Sigma Aldrich), L-sodium ascorbate ( $>98 \%$, Sigma Aldrich), $\mathrm{CuSO}_{4} \cdot 5 \mathrm{H}_{2} \mathrm{O}$ (>98\%, ChemSupply), NHS (98\%, Sigma Aldrich), and DCC ( $\geq 98 \%$, Sigma Aldrich) were all used as received.

Synthesis of Fluorescent PGMA NPs (RhB-PGMA NPs). A solution of $\mathrm{RhB}(20 \mathrm{mg})$ and PGMA $(100 \mathrm{mg})$ in MEK (50 $\mathrm{mL}$ ) was heated at $70{ }^{\circ} \mathrm{C}$ for $5 \mathrm{~h}$. This solution was then reduced in vacuo. The resultant RhB-PGMA polymer was precipitated in diethyl ether and washed three times with ether to remove ungrafted $\mathrm{RhB}$. The polymer was then dried and weighed. For NP synthesis, RhB-PGMA (100 mg) was dissolved in a 1:3 mixture of $\mathrm{CHCl}_{3}$ and $\operatorname{MEK}(8 \mathrm{~mL})$ to make up the organic phase. NPs were prepared by nonspontaneous emulsification of the organic phase in an aqueous solution of Pluronic F108 (1.25\% w/v, $60 \mathrm{~mL}$ ). The emulsion was homogenized using a probe-type ultrasonicator for $1 \mathrm{~min}$ at low power. Organic solvents were allowed to evaporate under a slow flow of $\mathrm{N}_{2}(\mathrm{~g})$ with stirring at $125 \mathrm{rpm}$ overnight. The resultant solution was centrifuged at $3000 \mathrm{~g}$ for $30 \mathrm{~min}$ to remove the excess polymer. The supernatant was collected and centrifuged at $20000 \mathrm{~g}$ for $30 \mathrm{~min}$ to collect the NPs, which were resuspended in $10 \mathrm{~mL}$ of Pluronic solution $(0.125 \% \mathrm{w} / \mathrm{v})$ for storage till further use. The equivalent dry mass of NPs was determined following freeze-drying of a known volume of NP suspension.

Synthesis of Propargylated NPs (Prop-RhB-PGMA NPs). NPs prepared as above were resuspended in MilliQ water at a final concentration of $2 \mathrm{mg} / \mathrm{mL}$. Propargylamine $(90 \mu \mathrm{L}, 2$ equiv) was added dropwise to $50 \mathrm{~mL}$ of the NP suspension under stirring. The reaction mixture was left stirring under an atmosphere of argon for $24 \mathrm{~h}$ at room temperature. Unreacted propargylamine was removed by repeated washing and centrifugation $(\times 4,35 \mathrm{~mL}$ of MilliQ water each wash) at 20 $000 \mathrm{~g}$ for $30 \mathrm{~min}$. The equivalent dry mass of NPs was determined after freeze-drying. Successful propargylamine attachment was confirmed using FTIR spectroscopy (Perkin Elmer, Spectrum One instrument with an ATR attachment).

Preparation of Azide-Functionalized FA (Azido-Folic Acid). A terminal azide functionality was introduced onto FA utilizing a previously reported method. ${ }^{20}$ FA $(500 \mathrm{mg})$ was dissolved in
DMSO $(20 \mathrm{~mL})$ containing $250 \mu \mathrm{L}$ of triethylamine. To this solution, $260 \mathrm{mg}$ of NHS (2.2 equiv) and $250 \mathrm{mg}$ of DCC (1.1 equiv) were added and stirred at room temperature for $24 \mathrm{~h}$. Then, $0.24 \mathrm{~g}$ of 3-azido-1-propylamine (2 equiv) was added to the reaction mixture, which was stirred for another $24 \mathrm{~h}$. The precipitated side product, dicyclohexylurea, was removed by filtration, and the crude product was precipitated in ethyl acetate. The crude product was dried overnight under vacuum. It was then dissolved in $1 \mathrm{M} \mathrm{NaOH}$, precipitated in $1 \mathrm{M} \mathrm{HCl}$, and purified by repeated washing and centrifugation $(\times 4$, ethanol/water $=1: 1,30 \mathrm{~mL}$ each wash). The obtained final product was dried under vacuum, and its identity was confirmed using FTIR (Perkin Elmer, Spectrum One instrument with an ATR attachment) and NMR $\left({ }^{1} \mathrm{H}\right.$, DMSO- $d_{6}$, $399.868 \mathrm{MHz}$, Varian $400 \mathrm{WB}$ spectrometer) spectroscopy. The yield was $72 \%$.

Synthesis of FA-Conjugated NPs Using the Click Chemistry Approach. Dispersions of propargylated NPs $(12 \mathrm{~mL}, 2 \mathrm{mg} /$ $\mathrm{mL})$ and azido-folic acid solutions $(5 \mathrm{~mL}, 9 \mathrm{mg} / \mathrm{mL})$ were separately prepared in freshly made $\mathrm{NH}_{4} \mathrm{HCO}_{3}$ buffer $(10 \mathrm{mM}$, $\mathrm{pH}$ 8.0) and mixed together while stirring. A freshly prepared sodium ascorbate solution ( $50 \mathrm{~mol} \%$ to the azido group, in $\mathrm{NH}_{4} \mathrm{HCO}_{3}$ buffer) followed by a $\mathrm{CuSO}_{4} \cdot 5 \mathrm{H}_{2} \mathrm{O}$ solution (20 mol \% to the azido group, in $\mathrm{NH}_{4} \mathrm{HCO}_{3}$ buffer) was added, and the mixture was left to stir at room temperature for $12 \mathrm{~h}$ under an atmosphere of argon. Afterwards, the reaction mixture was centrifuged at $20000 \mathrm{~g}$ for $30 \mathrm{~min}$ to collect the pelleted NPs. The NPs were repeatedly washed to remove unreacted azidofolic acid $\left(\times 4 ; 30 \mathrm{~mL} \mathrm{NH}_{4} \mathrm{HCO}_{3}\right.$ buffer, $10 \mathrm{mM}$, $\left.\mathrm{pH} 8.0\right)$ and dialyzed (Spectra/Por Float-A-Lyzer MWCO = $100 \mathrm{kDa}$ ) for $24 \mathrm{~h}$ against a solution of $0.125 \%(\mathrm{w} / \mathrm{v})$ Pluronic $\mathrm{F} 108$ dissolved in $2 \mathrm{~L}$ of $\mathrm{NH}_{4} \mathrm{HCO}_{3}$ buffer $(10 \mathrm{mM}, \mathrm{pH} 8.0)$. Successful attachment and the presence of FA were confirmed using FTIR and UV-vis absorption spectroscopy. The amount of FA present per unit mass of NPs was calculated from a FA standard curve prepared previously.

NP Characterization. NP samples were prepared at 0.20 $\mathrm{mg} / \mathrm{mL}$ in Pluronic F108 (0.125\% w/v in MilliQ water) for size and zeta potential measurements. Both size and surface charge were measured in triplicate using the Zetasizer Nano series ZEN 3600 (Malvern Instruments). Each measurement was averaged over 12 runs for size and 100 runs for zeta potential. Samples for TEM were prepared by deposition and drying of $10 \mu \mathrm{L}$ of the NP dispersion onto carbon-coated grids. TEM images were taken at $120 \mathrm{kV}$ on a JEOL JEM-2100 microscope.

In Vitro Testing. Cell Culture Materials. SKOV-3 cells (HTB-77, passage 81) and A549 cells (CCL-185, passage 27) were purchased from ATCC (American Type Culture Collection, Manassas, VA 20108 USA). HAL-15, a primary cell line isolated from normal human liver, was a kind gift from Prof. George Yeoh, the University of Western Australia. All cells were maintained in folate free RPMI 1640 cell culture medium (GIBCO) supplemented with 100 units $/ \mathrm{mL}$ penicillin $\mathrm{G}, 100 \mu \mathrm{g} / \mathrm{mL}$ streptomycin (Sigma Aldrich), and 10\% fetal bovine serum (Invitrogen). For immunofluorescence, the primary antibody used was an $\alpha$-tubulin (DM1A) mouse $\mathrm{mAb}$ (Cell signalling technologies) and the secondary antibody used was an AlexaFlour 488 Goat Anti-Mouse IgG antibody (Molecular Probes). DAPI was used for nuclei staining. Antibodies used for the flow cytometry analysis of receptor expression were allophycocyanin (APC) human FOLR1 mAb (FR $\alpha$ ) antibody (R\&D systems) and APC-tagged mouse IgG1 $\mathrm{K}$ Isotype control (R\&D systems). The antibody diluent used 
was phosphate-buffered saline (PBS) with $10 \%$ normal goat serum (Invitrogen) and 0.1\% Triton-X (Sigma Aldrich).

Flow Cytometric Analysis of FR $\alpha$ (FOLR1) Receptor Expression. Cells were harvested from an ongoing subculture flask $\left(75 \mathrm{~cm}^{2}\right.$ surface area, canted neck, Greiner cell culture flask supplied by Sigma Aldrich, Australia) and grouped into two sets of $5 \times 10^{5}$ cells in triplicate in $1.5 \mathrm{~mL}$ microcentrifuge tubes (Eppendorf, supplied by Sigma Aldrich, Australia). The cell samples were washed with fluorescence-activated cell sorting (FACS) buffer ( $1 \times$ PBS, pH 7.4 with $2 \%$ FBS) and resuspended in $40 \mu \mathrm{L}$ of the FACS buffer. APC-tagged human FOLR1 $\mathrm{mAb}(\mathrm{FR} \alpha)$ antibody ( $10 \mu \mathrm{L}$; for test samples) and 10 $\mu \mathrm{L}$ of APC tagged mouse IgG1 K Isotype control (for control samples) were added and mixed into each of the cell samples in the two sets, respectively. The samples were then incubated at 4 ${ }^{\circ} \mathrm{C}$ for $30 \mathrm{~min}$ in the dark. Post incubation, the excess antibody was removed by washing $(2 \times)$ with $500 \mu \mathrm{L}$ of FACS buffer followed by centrifugation at $300 \mathrm{~g}$ for $5 \mathrm{~min}$. Pelleted cells were resuspended in $200 \mu \mathrm{L}$ of FACS buffer and kept on ice until analysis. Analysis was done using a BD LSRFortessa SORP cell analyzer (BD Biosciences) within one hour of sample preparation. APC fluorescence was detected using a 660/20 band pass filter. A total of 80000 events were recorded and further gated for single cells that were analyzed for FOLR1 expression. Data were analyzed using the FlowJo Analysis software.

Toxicity Studies. SKOV-3 (passage 83), A549 (passage 31), and HAL-15 cells were separately seeded in 12-well plates (Greiner Bio-One Cell star, supplied by Sigma Aldrich) at a density of 50000 cells per well with $2 \mathrm{~mL}$ of folate-free RPMI 1640 culture medium (GIBCO; supplemented with 100 units/ $\mathrm{mL}$ penicillin $\mathrm{G}, 100 \mu \mathrm{g} / \mathrm{mL}$ streptomycin, and $10 \%$ fetal bovine serum). After overnight incubation at $37{ }^{\circ} \mathrm{C}$ in $5 \% \mathrm{CO}_{2}$, the cells were washed with prewarmed Dulbecco's phosphatebuffered saline (DPBS) and incubated with RPMI 1640 culture medium [GIBCO; supplemented with 100 units $/ \mathrm{mL}$ penicillin $\mathrm{G}, 100 \mu \mathrm{g} / \mathrm{mL}$ streptomycin (Sigma Aldrich), and $10 \%$ fetal bovine serum (Invitrogen)] containing RhB-PGMA NPs or FA-RhB-PGMA NPs at the concentrations of 1, 10, and 100 $\mu \mathrm{g} / \mathrm{mL}$. Control cells were incubated with culture media only. After $72 \mathrm{~h}$ of incubation at $37^{\circ} \mathrm{C}$ in an atmosphere of $5 \% \mathrm{CO}_{2}$, $200 \mu \mathrm{L}$ of MTS reagent was added into each well and incubated for $3 \mathrm{~h}$ at $37{ }^{\circ} \mathrm{C}$. Absorption was read at $492 \mathrm{~nm}$ using an Enspire 2300 multimodal plate reader (Perkin Elmer). Experiments were conducted in triplicate, and one-way ANOVA with Tukey's test at $95 \%$ confidence level was applied post hoc to compare unpaired means of absorbance values $(n=$ 3).

NP Uptake Studies. SKOV-3 (passage 81) and A549 cells (passage 27) were plated at a density of 50000 cells per well on poly-(L-lysine)-coated glass coverslips placed in a 12 -well plate. After $24 \mathrm{~h}$ of incubation in $2 \mathrm{~mL}$ of folate-free RPMI 1640 culture medium (GIBCO; supplemented with 100 units/mL penicillin $\mathrm{G}, 100 \mu \mathrm{g} / \mathrm{mL}$ streptomycin and $10 \%$ FBS), the cells were incubated for $12 \mathrm{~h}$ with either $10 \mu \mathrm{g} / \mathrm{mL}$ RhB-PGMA NPs or $10 \mu \mathrm{g} / \mathrm{mL}$ FA-RhB-PGMA NPs prepared in culture media. After incubation, media and NPs were removed, and the cells were washed $3 \times$ with DPBS and fixed using a paraformaldehyde solution ( $4 \% \mathrm{w} / \mathrm{v}$ in MilliQ water). The fixed cells were washed $3 \times$ with PBS and further incubated with $\alpha$-tubulin (DM1A) mouse mAb (1:4000 in antibody diluent) for $30 \mathrm{~min}$ at room temperature. The unattached antibody was removed by washing $2 \times$ with PBS. These cells were further incubated with AlexaFlour 488 Goat Anti-Mouse IgG antibody (1:400 in antibody diluent) for $30 \mathrm{~min}$ at room temperature. The unattached antibody was removed by washing with PBS $(\times 2)$, and the cells were incubated with a Hoechst solution (1:10 000 in PBS) for 5 min. The cells were finally washed with PBS $(\times 2)$, and the samples were mounted onto glass slides using fluoromount gold mounting media for analysis using a confocal microscope (Leica TCS SP2, Nikon A1Si). Confocal images presented in this paper are maximum projections of $\mathrm{Z}$ Stacks.

Statistical Analysis. Statistical comparisons were made using one-way ANOVA $(p<0.05)$ with Tukey's (corrected for multiple comparison) post hoc test (GraphPad version 6.0).

\section{ASSOCIATED CONTENT}

\section{Supporting Information}

The Supporting Information is available free of charge on the ACS Publications website at DOI: 10.1021/acsomega.6b00239.

UV-vis absorption spectrum for FA-RhB-PGMA NPs, estimation of FA content on NPs, ${ }^{1} \mathrm{H}$ NMR for FA and azido-FA, flow cytometric analysis and comparison of FR $\alpha$ expression on SKOV-3, A-549, and HAL-15 cells (PDF)

\section{AUTHOR INFORMATION}

\section{Corresponding Authors}

*E-mail: swaminatha.iyer@uwa.edu.au (K.S.I.).

*E-mail: nicole.smith@uwa.edu.au (N.M.S.).

\section{Author Contributions}

The manuscript was written through contributions of all authors. All authors have given approval to the final version of the manuscript.

\section{Funding}

This work was funded by the Australian Research Council (ARC) and the National Health \& Medical Research Council (NHMRC).

\section{Notes}

The authors declare no competing financial interest.

\section{ACKNOWLEDGMENTS}

The authors would like to thank Prof. Igor Luzinov and Dr. Yuriy Galabura from the Department of Materials Science and Engineering at Clemson University, South Carolina, USA, for their generous gift of the PGMA polymer, and Dr. Marck Norret from the School of Chemistry and Biochemistry at the University of Western Australia, Australia, for his advice on "click" chemistry reactions. The authors acknowledge the facilities and the scientific and technical assistance of the Australian Microscopy \& Microanalysis Research Facility at the Centre for Microscopy, Characterisation \& Analysis, the University of Western Australia, funded by the university and the State and Commonwealth governments.

\section{ABBREVIATIONS}

NP, nanoparticle; PGMA, poly(glycidyl methacrylate); FA, folic acid; FR, folate receptor; FR $\alpha$, folate receptor- $\alpha$; CuAAC, copper-catalyzed alkyne azide cycloaddition; $\mathrm{RhB}$, rhodamine B; NHS/DCC, $N$-hydroxysuccinamide/ $N, N^{\prime}$-dicyclohexylcarbodiimide; FTIR, Fourier transform infrared; NMR, nuclear magnetic resonance; UV-vis, ultraviolet-visible 


\section{REFERENCES}

(1) Allen, T. M. Ligand-targeted therapeutics in anticancer therapy. Nat. Rev. Cancer 2002, 2, 750-763.

(2) (a) Chari, R. V. J. Targeted Cancer Therapy: Conferring Specificity to Cytotoxic Drugs. Acc. Chem. Res. 2008, 41, 98-107. (b) Srinivasarao, M.; Galliford, C. V.; Low, P. S. Principles in the design of ligand-targeted cancer therapeutics and imaging agents. Nat. Rev. Drug Discovery 2015, 14, 203-219. (c) Collins, I.; Workman, P. New approaches to molecular cancer therapeutics. Nat. Chem. Biol. 2006, 2, 689-700.

(3) Weissleder, R.; Kelly, K.; Sun, E. Y.; Shtatland, T.; Josephson, L. Cell-specific targeting of nanoparticles by multivalent attachment of small molecules. Nat. Biotechnol. 2005, 23, 1418-1423.

(4) Nicolas, J.; Mura, S.; Brambilla, D.; Mackiewicz, N.; Couvreur, P. Design, functionalization strategies and biomedical applications of targeted biodegradable/biocompatible polymer-based nanocarriers for drug delivery. Chem. Soc. Rev. 2013, 42, 1147-1235.

(5) Valetti, S.; Mura, S.; Noiray, M.; Arpicco, S.; Dosio, F.; Vergnaud, J.; Desmaële, D.; Stella, B.; Couvreur, P. Peptide conjugation: Before or after nanoparticle formation? Bioconjugate Chem. 2014, 25, 19711983.

(6) Avvakumova, S.; Colombo, M.; Tortora, P.; Prosperi, D. Biotechnological approaches toward nanoparticle biofunctionalization. Trends Biotechnol. 2014, 32, 11-20.

(7) Algar, W. R.; Prasuhn, D. E.; Stewart, M. H.; Jennings, T. L.; Blanco-Canosa, J. B.; Dawson, P. E.; Medintz, I. L. The Controlled Display of Biomolecules on Nanoparticles: A Challenge Suited to Bioorthogonal Chemistry. Bioconjugate Chem. 2011, 22, 825-858.

(8) Kolb, H. C.; Finn, M. G.; Sharpless, K. B. Click chemistry: Diverse chemical function from a few good reactions. Angew. Chem., Int. Ed. 2001, 40, 2004-2021.

(9) (a) Lucock, M. Folic acid: Nutritional biochemistry, molecular biology, and role in disease processes. Mol. Genet. Metab. 2000, 71, 121-138. (b) Locasale, J. W. Serine, glycine and one-carbon units: Cancer metabolism in full circle. Nat. Rev. Cancer 2013, 13, 572-583. (c) Anderson, O. S.; Sant, K. E.; Dolinoy, D. C. Nutrition and epigenetics: An interplay of dietary methyl donors, one-carbon metabolism and DNA methylation. J. Nutr. Biochem. 2012, 23, 853859.

(10) Xia, W.; Low, P. S. Folate-targeted therapies for cancer. J. Med. Chem. 2010, 53, 6811-6824.

(11) Parker, N.; Turk, M. J.; Westrick, E.; Lewis, J. D.; Low, P. S.; Leamon, C. P. Folate receptor expression in carcinomas and normal tissues determined by a quantitative radioligand binding assay. Anal. Biochem. 2005, 338, 284-293.

(12) Matherly, L. H.; Goldman, I. D. Membrane transport of folates. Vitam. Horm. 2003, 66, 403-456.

(13) (a) Guo, X.; Shi, C.; Wang, J.; Di, S.; Zhou, S. pH-triggered intracellular release from actively targeting polymer micelles. Biomaterials 2013, 34, 4544-4554. (b) Shi, C.; Guo, X.; Qu, Q.; Tang, Z.; Wang, Y.; Zhou, S. Actively targeted delivery of anticancer drug to tumor cells by redox-responsive star-shaped micelles. Biomaterials 2014, 35, 8711-8722. (c) Werner, M. E.; Karve, S.; Sukumar, R.; Cummings, N. D.; Copp, J. A.; Chen, R. C.; Zhang, T.; Wang, A. Z. Folate-targeted nanoparticle delivery of chemo- and radiotherapeutics for the treatment of ovarian cancer peritoneal metastasis. Biomaterials 2011, 32, 8548-8554. (d) Liu, Y.; Li, K.; Pan, J.; Liu, B.; Feng, S.-S. Folic acid conjugated nanoparticles of mixed lipid monolayer shell and biodegradable polymer core for targeted delivery of Docetaxel. Biomaterials 2010, 31, 330-338. (e) Lale, S. V.; Kumar, A.; Prasad, S.; Bharti, A. C.; Koul, V. Folic acid and trastuzumab functionalized redox responsive polymersomes for intracellular doxorubicin delivery in breast cancer. Biomacromolecules 2015, 16, 1736-1752. (f) Rolfe, B. E.; Blakey, I.; Squires, O.; Peng, H.; Boase, N. R. B.; Alexander, C.; Parsons, P. G.; Boyle, G. M.; Whittaker, A. K.; Thurecht, K. J. Multimodal polymer nanoparticles with combined ${ }^{19} \mathrm{~F}$ magnetic resonance and optical detection for tunable, targeted, multimodal imaging in vivo. J. Am. Chem. Soc. 2014, 136, 2413-2419. (g) Liu, X.; Miller, A. L., II; Yaszemski, M. J.; Lu, L.
Biodegradable and crosslinkable PPF-PLGA-PEG self-assembled nanoparticles dual-decorated with folic acid ligands and Rhodamine $B$ fluorescent probes for targeted cancer imaging. RSC $A d v$. 2015, 5, 33275-33282. (h) Paulmurugan, R; Bhethanabotla, R.; Mishra, K.; Devulapally, R.; Foygel, K.; Sekar, T. V.; Ananta, J. S.; Massoud, T. F.; Joy, A. Folate Receptor-Targeted Polymeric Micellar Nanocarriers for Delivery of Orlistat as a Repurposed Drug against Triple-Negative Breast Cancer. Mol. Cancer Ther. 2016, 15, 221-231.

(14) Chen, C.; Ke, J.; Zhou, X. E.; Yi, W.; Brunzelle, J. S.; Li, J.; Yong, E.-L.; Xu, H. E.; Melcher, K. Structural basis for molecular recognition of folic acid by folate receptors. Nature 2013, 500, 486-489.

(15) Elias, D. R.; Poloukhtine, A.; Popik, V.; Tsourkas, A. Effect of ligand density, receptor density, and nanoparticle size on cell targeting. Nanomedicine 2013, 9, 194-201.

(16) Sapsford, K. E.; Algar, W. R.; Berti, L.; Gemmill, K. B.; Casey, B. J.; Oh, E.; Stewart, M. H.; Medintz, I. L. Functionalizing nanoparticles with biological molecules: Developing chemistries that facilitate nanotechnology. Chem. Rev. 2013, 113, 1904-2074.

(17) Tsyalkovsky, V.; Klep, V.; Ramaratnam, K.; Lupitskyy, R.; Minko, S.; Luzinov, I. Fluorescent reactive core-shell composite nanoparticles with a high surface concentration of epoxy functionalities. Chem. Mater. 2008, 20, 317-325.

(18) Mo, J.; Eggers, P. K.; Yuan, Z.-X.; Raston, C. L.; Lim, L. Y. Paclitaxel-loaded phosphonated calixarene nanovesicles as a modular drug delivery platform. Sci. Rep. 2016, 6, 23489.

(19) Hein, C. D.; Liu, X.-M.; Wang, D. Click chemistry, a powerful tool for pharmaceutical sciences. Pharm. Res. 2008, 25, 2216-2230.

(20) Liu, L.; Zheng, M.; Renette, T.; Kissel, T. Modular synthesis of folate conjugated ternary copolymers: Polyethyl-enimine-graft-polycaprolactone-block-poly (ethylene glycol)-folate for targeted gene delivery. Bioconjugate Chem. 2012, 23, 1211-1220.

(21) (a) Poe, M. Acidic dissociation constants of folic acid, dihydrofolic acid, and methotrexate. J. Biol. Chem. 1977, 252, 37243728. (b) Bhattacharjee, S. DLS and zeta potential-What they are and what they are not? J. Controlled Release 2016, 235, 337-351. 